\title{
An affective approach to modelling intentions to use technologies for social distancing in hotels
}

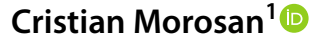

Received: 31 May 2021 / Revised: 26 August 2021 / Accepted: 22 October 2021 /

Published online: 3 November 2021

(c) The Author(s), under exclusive licence to Springer-Verlag GmbH Germany, part of Springer Nature 2021

\begin{abstract}
In response to the global COVID-19 pandemic, the U.S. hotels have deployed service models that facilitate social distancing by using information technology. Based on emotion theories, this study built a conceptual model that explains consumers' intentions to use several personal and public technologies for social distancing in hotels (e.g., electronic menus, mobile apps). The model tested relationships between trust in the hotel, trust in system, technology anxiety, anticipated positive and negative emotions, and intentions to use technologies for social distancing. Using data collected from 1000 U.S. hotel guests, it was found that intentions to use technologies for social distancing were predominantly influenced by positive anticipated emotions, which in turn were influenced by trust in the hotel and technology anxiety. Several implications for academia and industry are provided.
\end{abstract}

Keywords Public technology $\cdot$ Hotel $\cdot$ Anticipated emotions $\cdot$ Technology anxiety Coronavirus

\section{Introduction}

The global COVID-19 pandemic and general population's anxiety regarding the risk of illness guided hotels to utilize their existing information technology (IT) infrastructure to create new hotel servicescapes and enhance safety. Particularly, an important aspect of adapting the hotel operations during the pandemic is facilitating social distancing and reducing the contact among consumers and staff (Solay 2020). Although there are many ways in which the hotels accomplished this goal,

\footnotetext{
This research has been conducted with the support of Hospitality Financial and Technology Professionals (HFTP).

Cristian Morosan

cmorosan@uh.edu

1 Conrad N. Hilton College of Hotel and Restaurant Management, University of Houston, 4800

Calhoun Rd., Houston, TX 77204, USA
} 
an important aspect of social distancing in hotels remains the use of IT. Hotels have approached social distancing via IT by rethinking their IT-based services (e.g., selfcheck-in) and encouraging guests and staff to use IT to avoid human contact. Such IT includes mobile apps, touchless payments, or QR code readers for electronic menus. In these new conditions, the use of such technologies (thereafter called Technologies for Social Distancing (TSD)) by guests becomes critical for the new IT-based services to be effective in safeguarding health in hotels.

While there are no studies examining TSD in U.S. hotels, the literature investigating critical aspects of hospitality has begun to provide insight into managerial aspects of hotel management during the pandemic. For example, Shin and Kang (2020) found that low levels of interaction via IT could reduce perceived health risks and that health risks mediates the relationship between expected interaction and booking intentions. Moreover, Bonfanti et al. (2021) found that several measures, including investments in technology and digital innovations can have positive impacts on hotels during the pandemic. While the COVID-19 related literature is emerging, the IT literature remains rich in conceptualizations of intentions and use of IT in hotels (Wang et al. 2015). This vast body of literature illustrates how consumers develop intentions to use such IT in normal consumption situations, when the use of such systems is voluntary (Morosan and DeFranco 2016b). While the pandemic does not necessarily force consumers to adopt TSD, the risk of COVID-19 when not using TSD may alter consumers' motivations to use such systems. Given that the IT utilization by consumers during the pandemic is not understood in hospitality, this marks a very important first research gap. Leaving this gap unaddressed can result in a severe misunderstanding of motivations that drive consumers to use IT that are critical to safeguarding health in hotels during the pandemic.

Given the uncertain course of the pandemic and the different responses from the multiple layers of government, businesses, and consumers, it is difficult to gauge a unified and consistent cognitive response of U.S. consumers to the risk of COVID19 when traveling. This creates conditions for the pandemic to take an emotional toll on both consumers and hotel staff, by stimulating emotional responses that reflect the utilization of TSD. Consumers' emotions could be stimulated by their perceptions of risk of infection with COVID-19, while staff's emotions may be stimulated by risk of infection with COVID-19 exacerbated by the need to work during the pandemic to avoid unemployment. Thus, consumers' emotional responses to the various measures taken by hotels to enhance social distancing could be seen as critical factors affecting their intentions to use TSD. Yet, the literature in IT adoption is limited to the examination of predominantly cognitive factors leading to adoption (Morosan and DeFranco 2016b), which marks a second research gap. Not addressing this gap resorts to the logic that consumers' intentions can be explicated exclusively via cognitive concepts, which misses an entire category of critical determinants of behavior (Tsaur et al. 2015).

In their effort to address the pandemic, but without the predictable pre-pandemic revenue streams, many hotels were not able to deploy newer technologies to enhance social distancing. Instead, they relied on existing ones. Given the amalgamation of various hotel IT, they can be classified in many ways (e.g., front-of-the-house vs. back-of-the-house systems, marketing vs. accounting systems, etc.). However, as the 
pandemic emphasized the notion of safeguarding health by reducing the frequency of touching the same public objects (e.g., payment terminals), hotel technology can now be classified into personal vs. public IT used in hotels. For example, personal IT include systems that consumers can use without physically touching any publicly available hardware, such as mobile apps or QR-codes. In contrast, public IT are requiring users to touch a piece of publicly available hardware (i.e., available for everyone to touch) to accomplish a task, such as kiosks or business office computers. Yet, the IT adoption literature has not made this distinction between the two types of self-service technologies, marking a third important gap. As consumers may form different intentions depending on the degree of public exposure of a technology during the pandemic, addressing this gap can lead to a more precise explanation of hotel guests' intentions to use TSD in hotels.

Addressing these three gaps simultaneously, this study built a conceptual model aimed at explaining consumers' intentions to use personal and public TSD in hotels during the COVID-19 pandemic. Specifically, utilizing legacy theories of emotions (Perugini and Bagozzi 2001) this study included trust in the hotel and trust in the technology, consumers' technology anxiety, and their anticipated positive and negative emotions as antecedents of intentions to use two types of TSD in hotels. This way, this study offers a more accurate conceptualization of the task-technology environment within adoption literature outside of the normal voluntary IT settings. At the same time, this approach addresses weaknesses in IT adoption models by integrating emotion-based artifacts in models explaining IT adoption in experiential service settings such as hotels.

\section{Review of literature}

\subsection{Public vs. personal technologies for social distancing in hotels}

Yet, certain legacy functions such as distribution and promotion have remained anchored in traditional systems (e.g., property management system to retail interface), which require the utilization by of consumers' own devices to access such products. While hotel legacy functions have been examined by the literature (Morosan and Jeong 2008), the recent evolution of such systems warrants new investigations into the way they facilitate access and consumption of hotel services (Cobos et al. 2016). For example, the extensive investments in mobile apps by hotels allowed apps to fulfill better personalization roles while requiring consumers to disclose relevant private information to hotels (Sarmah et al. 2017). Moreover, the travel literature added insight on the potential of IT in shaping consumers' information search and decision making (Shao et al. 2020).

The success of such technologies is grounded in the consumers' mass adoption. Yet, success relies on a fundamental assumption: that consumers have the necessary devices and Internet access to utilize such IT tools (Venkatesh et al. 2012). This aspect of adoption has been validated extensively in the literature as "facilitating conditions", including in hospitality research (Morosan and DeFranco 2016b). Based on this logic, many legacy systems evolved and new 
systems have been deployed that require the use of consumers' own hardware, software, or skills. As a result, today's hotel IT landscape is heavily anchored in a variety of systems such as reservation websites, apps, and the corresponding payment and fulfillment systems (Ahn and Seo 2018). Such systems have been investigated by scholars, who eventually found convergent results that explain various adoption facets. For example, there is agreement that hotel guests' adoption of electronic payments is influenced by personalization, privacy concerns, and consumers' involvement (Morosan and DeFranco 2016c).

The abundant utilization of IT by hotel guests also encouraged developers to deploy on-property systems to facilitate personalization, easy access to services and an overall higher value proposition (Wei et al. 2017). Such systems include self-service kiosks, in-room devices (e.g., tablets), or electronic menus in restaurants, which allow consumers to create frictionless booking-arrivalstay-departure consumption sequences. Moreover, the utilization of such IT facilitated a new level of personalization of hotel services, allowing consumers to co-create and appropriate a high value proposition (Harkison 2018). The literature has been prompt to examine multiple aspects of such IT, confirming the critical role of system usefulness (Wang and Li 2019), consumers' habits (Escobar-Rodríguez and Carvajal-Trujillo 2014), and their perceptions of security/privacy in the adoption of such systems (Chan and Lam 2013).

While the literature provided valuable insight into the drivers of such systems in normal business settings, it is unclear whether the same motivations are sufficient to influence consumers' use behaviors during the pandemic. While the pre-pandemic value of hotel IT was primarily appropriated by consumers due to convenience and optimization (Morosan and DeFranco 2016a) and playfulness value of a task (Marques and Borba 2017), the TSD systems used during/ post-pandemic create value by safeguarding health. TSD facilitate a new type of experience, which must mediate the balance between technology that keeps people safe and the human interaction which stays at the core of hotel services. For example, many hotels are relying more extensively on their IT infrastructure to guide their guests to interact less with the staff (Kohlmayr 2020). Moreover, in foodservice, trade publications reported an increasing utilization of QR code readers and electronic menus (Guszkowski 2020). This logic shifts the focus of the most critical element of IT adoption-the task-technology environment- to a context where the main IT task is minimizing physical contact and ultimately protecting users from being sick. Consumers' responses to the new context of IT use in hotels may have shifted dramatically even though the primary tasks addressed by such systems may have not. As health risk is recognized as being associated with emotional responses (Chien et al. 2017), the use of TSD to safeguard health in the post-pandemic hotel context are very likely associated with consumers' emotions. In such conditions, the use of TSD moves from voluntary to quasi-mandatory, as they are driven by a mix of emotional factors that stimulate behavioral responses to the new hotel service environment. 


\subsection{Theoretical model development}

\subsubsection{Theoretical justification}

The uniqueness of the COVID-19 pandemic conditions placed the literature findings in a situation where the applicability of theoretical relationships could be adapted to better explain the current business and societal environment. In this context, it is difficult to rely on only one type of artifacts-cognitive or affective- to examine consumers' responses to stimuli and their behaviors. Consumers tend to become emotionally charged, and they rely on emotions for guiding intentions and behaviors (Richard and Chebat 2016). Therefore, to best understand consumers' intentions to use TSD in hotels, the development of the conceptual model had to be based on emotional artifacts that influence intentions.

While the literature is heavily based on cognitive antecedents of adoption (Venkatesh et al. 2012), recent research suggests that relying exclusively on cognitive antecedents can lead to a nuanced view of adoption. For example, consumers' perceptions of usefulness of a system (e.g., robot) may be different in task-technology environments that are characterized by credence attributes (e.g. hospital) than in those with experiential attributes (e.g., café), while other system perceptions such as privacy and system trust are not environmental-dependent (Park et al. 2021). Thus, in recent years, scholars have increasingly advanced findings according to which emotions are critical contributors to an individual's motivations to adopt IT (Beaudry and Pinsonneault 2010). For example, emotional appeal has been recently recognized as an important factor resulting from using multisensory technologies, along with cognitive or behavioral factors such as visual appeal and purchasing intentions (Mishra et al. 2020).

The increasing inclusion of emotion constructs is based on two tenets: (1) that IT stimulates users' emotional reactions in situations when regular routine is interrupted (Rafaeli and Vilnai-Yavetz 2004) and cognitive-based models cannot fully capture the IT-adoption behavior antecedents (Beaudry and Pinsonneault 2010). Moreover, the literature increasingly recognizes the cognitive aspects of emotion regulation and elicitation, particularly the role of cognition in emotion elicitation (de Houwer and Hermans 2010). In the context of TSD use during/post-pandemic, the general hotel-guest interaction protocols have changed to stimulate less physical contact, which could elicit the development and appraisal of certain emotions strong enough to guide TSD behaviors. To recognize this critical aspect of TSD adoption, the conceptual model in the study is based on emotion theory (Westbrook 1987). While there are many theoretical approaches to the study of the role of emotions in influencing pro-IT behaviors (e.g., Brown et al. 2004), the literature generally converges to the thesis that emotions (positive and negative) (Cenfetelli 2004) influence consumers' IT adoption (George and Dane 2016). Specifically, positive emotions such as enjoyment (Koufaris 2002) and flow (Trevino and Webster 1992) have a positive effect on IT adoption, while negative emotions, such as anxiety (Venkatesh et al. 2003) are negatively related to IT adoption.

This study also adopts the view of valanced emotions: positive and negative (Westbrook 1987). This is an established aspect of dimensional theories of emotion, 
which posit that there are key dimensions (e.g., valence, arousal) that are critical in the conceptualization of emotional stimuli (Brosch et al. 2010). Such theories allow for the differentiation between two different motivational systems-appetitive and aversive-which stay at the foundation of approaching and withdrawal behaviors (Davidson and Irwin 1999). In this study, given the potential impact of the decision to utilize (vs. to avoid) TSD on a hotel's guest health, conceptualizing emotional valence is required for three important reasons: (1) cognitive elaboration is grounded in affective elaboration (Blanchette and Richards 2010), (2) the examination of emotionally-charged consumption scenarios is insufficient if based only on cognitive artifacts (Beaudry and Pinsonneault 2010), and (3) an increasing body of literature reflects the notion that consumers' affective responses during important crises (Lacasse 2017) affect the way they behave.

Most literature is based on examining IT adoption intentions to use in voluntary settings (Lien et al. 2019). For example, the adoption of websites or apps is based on truly voluntary adoption (Salehi-Esfahani and Kang 2019). However, the global pandemic provides less than voluntary settings for the utilization of TSD in hotels, given the potential health risk resulting from not using TSD or requirements placed on consumers if they want to receive service. Therefore, while the literature in IT adoption remains relevant to providing artifacts for the development of the current model, it also considers the non-voluntary utilization of IT. Therefore, this study adapted constructs from studies in non-voluntary settings such as IT used for air travel or border control (Morosan 2016). In addition to the predominant affective artifacts of this model, the model also included trust, which it is important in context characterized by uncertainty, risk, and interdependence (Mayer et al. 1995). Thus, the conceptual model in this study was built with two cognitive (i.e., trust in hotel and trust in system) and three affective (e.g., anticipated positive and negative emotions, and technology anxiety) antecedents of intentions to use TSD in hotels.

\subsubsection{Trust in hotel}

Trust reflects a situation when one party relies on the actions of another party when the first party does not have control over the actions of the other party (Yousafzai et al. 2005). While trust has been studied extensively in consumer psychology, it has very important implications in services. In services, trust was found to influence consumers' behaviors, especially when a direct interaction between the consumer and the company staff is not necessarily possible (Palvia 2009). That is, when consumers trust the commercial entity from which they buy, they are likely to engage more with the entity and feel a lesser degree of risk attributable to the products they are purchasing (Sheppard and Sherman 1998). This logic applies to the hotel industry, where trust has been found to influence consumers behavior (Liang et al. 2018). This aspect is important especially because hotel experiences are highly intangible and consumers encounter asymmetric information, which prevents them from developing a clear set of descriptors of the hotel service experience (Kotler et al. 2016). Overall, the literature generally supports the notion that trust allows consumers to develop behaviors toward a commercial entity/brand (Shao et al. 2019). 
The existing literature provides important hints to the role of trust in developing consumers perceptions, emotions, or beliefs, which could influence behavior (Fang et al. 2014). For example, consumers' trust influences their brand relationship quality (Akrout and Nagy 2018) and intentions to engage in e-commerce (Liu et al. 2005). Hotels are in a unique position to develop trust in consumers. This is because hotel guests encounter situations where they must rely on hotels to protect their privacy, safety, nutrition, etc. Moreover, the repeated interactions between hotels and guests that are successful can result in trust (Cochard et al. 2004). Thus, consumers who are likely to trust the hotel could also believe that the hotel can deploy procedures and technologies that will safeguard their health during the pandemic. Yet, to fully safeguard their health, hotel consumers use TSD to perform their hotel tasks. As a result, the development of trust in the hotel can influence important positive anticipated emotions such as self-assurance, delight, or pride. Based on the discussion above, the following hypothesis has been developed.

H1: Consumers' trust in hotel positively influences their anticipated positive emotions regarding the use of TSD in hotels.

Given the current health risks, consumers who trust the hotel are also likely to view their inability to utilize TSD in hotels as a failure, therefore strengthening their negative anticipated emotions. Specifically, consumers trust the hotel and believe that the TSD-based hotel procedures will help them successfully social distance. Conversely, any inability to use TSD could put consumers in a position of fear. Accordingly, the following hypothesis has been developed.

H2: Consumers' trust in hotel positively influences their anticipated negative emotions regarding the use of TSD in hotels.

\subsubsection{Trust in system}

While organizations strive to deploy trustworthy systems, it is possible that not all systems deployed by an organization are perceived as trustworthy by consumers. Especially in hotels, where services are heterogenous, and the IT deployed are different from one task to another within the same property, trust in the hotel may not be sufficient to explain consumers' behaviors (Morosan and DeFranco 2015). Moreover, in hotels, consumers are likely to see IT deployed by multiple vendors (Nyheim and Connolly 2012), which adds to the heterogeneity of IT services available to guests. Therefore, it is important to recognize the concept of trust in the system, which reflects the degree of trust that consumers place in a specific system capable of allowing them to accomplish a particular task (Zimmer et al. 2010). The concept of trust in a system has only recently began to gain attention as an antecedent of IT-related behaviors. For example, trust in system influences consumers' willingness to disclose personal information to hotel apps (Morosan and DeFranco 2015). Recently, trust in system was found to influence users' perceived usefulness and ease of use of AI service robots (Park et al. 2021).

Perceptual theorists proposed that the mechanisms involved in emotion have a common ground with the mechanisms involving perception, and that perceptions and emotions arise automatically (Moors 2010). Thus, in a business context characterized by a variety of responses (e.g., cognitive, behavioral) to 
the way consumers perceive that a system is capable of facilitating a task, it is possible that consumers' perceptions of various systems could result in emotional responses, akin to the way such perceptions result in attitudinal evaluations (Akroush and Al-Debei 2015), perceptions, and behaviors (Morosan and DeFranco 2019). In the hotel context during the pandemic, consumers may wonder whether the TSD designed to safeguard health can be trusted. In such situations, trust is difficult to form within the limited time of a guest-IT interaction (Park et al. 2021), especially given the uncertainty of IT deployment during the pandemic. Such level of uncertainty may result in an inability to form accurate health risk perceptions, which may result in emotional responses that can be ambivalent. For example, if TSD is perceived as trustworthy, consumers may believe that their risk of contamination with the coronavirus is relatively lower, stimulating both positive and negative emotions. Accordingly, the following two hypotheses were developed.

H3: Consumers' trust in system positively influences their anticipated positive emotions regarding the use of TSD in hotels.

H4: Consumers' trust in system positively influences their anticipated negative emotions regarding the use of TSD in hotels.

\subsubsection{Technology anxiety}

Technology anxiety refers to an emotional state where consumers feel discomfort regarding their use of technology (Kim and Forsythe 2008). This has been recognized as occurring when consumers are facing specific unknown systems, which can result in avoidance or reduced use of technology (Parasuraman 2000). The use of technology anxiety has been limited in the IT literature (Park et al. 2019). Yet, its role in shaping consumers' motivations to use IT has been unequivocally recognized (Yang and Forney 2013). The role of technology anxiety is extremely important in the hotel service context for two reasons. First, consumers, especially leisure consumers, may interact with hotel technologies on an irregular basis. Thus, over time they may forget how to interact with a system, which puts them in a situation where their evaluation of the technology use may be negative. This is exacerbated by the fact that general hotel tasks that could be accomplished using the technology can also be accomplished very easily by communicating with staff members, due to the hospitable nature of hotel services. Second, the COVID-19 pandemic could have shifted the motivations of consumers regarding the use of IT. As many technologies are placed in hotels to avoid interactions between guests and staff, consumers may feel that their lack of ability to complete tasks with such technologies can put them at risk of COVID19 by forcing them into interactions with staff. As a result, consumers who are anxious about the use of technology may also develop negative anticipated emotions relative to the use of TSD in hotels, according to the following hypothesis.

H5: Consumers' technology anxiety positively influences their anticipated negative emotions regarding the use of TSD in hotels. 


\subsubsection{Anticipated emotions}

While emotions have been studied extensively in the business literature, their utilization in the IT literature is relatively recent (Piçarra and Giger 2018). This is because many legacy IT adoption models have been grounded in cognitive artifacts that explain IT use (Venkatesh et al. 2003). Yet, increasingly, scholars have recognized the importance of incorporating emotional artifacts into the predominantly cognitive based theoretical models that explain the utilization of it in order to have a more nuanced view of the motivations that drive consumers behavior (Wang et al. 2018). Hospitality makes no exception, especially given the highly experiential character of the its services (Kim et al. 2013). Hotels are designed to accommodate to basic needs, but in order to differentiate among different classes or brands of hotels, various attributes of the hotel experience have been designed to stimulate emotions (Kotler et al. 2016). Yet, it remains unknown what role the emotions play in the utilization of certain technologies, especially in constraining conditions such as the current pandemic.

Especially during the pandemic, consumers are likely to respond emotionally to the types of servicescapes that are created via IT. This is because it is difficult to obtain information that could clearly guide consumers cognition of the various processes that prevent people from getting sick in hotels. In this case, consumers' emotions can play important roles in the way they shape their behavior. Therefore, their emotions are likely to represent fundamental facilitators or barriers in the use of any artifact that enhances their value of the experience while preventing them from getting sick. In such conditions, it is likely that the positive emotions associated with the use of TSD technologies in hotels are likely to influence their intentions to use IT (Morosan 2020).

According to this discussion, the following four hypotheses were developed.

H6: Consumers anticipated positive emotions positively influence their intentions to use personal TSD in hotels.

H7: Consumers anticipated positive emotions positively influence their intentions to use public TSD in hotels.

Anticipated negative emotions have been recognized as antecedents of consumers' decision-making processes (Perugini and Bagozzi 2001). Generally framed as anticipated regret, they have been found to be important in alleviating behavioral expectations regarding risky behavior (Parker et al. 1995) and would increase the expectations that individuals would engage in behaviors that mitigate risk (Richard et al. 1995). Specifically, individuals could consider the emotional consequences resulting from achieving (e.g., using TSD successfully) or failing (e.g., failing to use TSD) a goal (e.g., the task of using TSD in hotels) (Perugini and Bagozzi 2001). Such pre-factual appraisals allow individuals to imagine the emotional consequences of their behavior when deciding to perform the behavior (Gleicher et al. 1995). Accordingly, consumers with high negative anticipated emotions are likely to engage in behaviors that would support their main task-using TSD to complete hotel tasks and reduce the risk of contamination with coronavirus.

H8: Consumers anticipated negative emotions positively influence their intentions to use personal TSD in hotels. 
H9: Consumers anticipated negative emotions positively influence their intentions to use public TSD in hotels.

\subsubsection{Intentions}

Intentions are very important determinants of actual behavior (Fishbein and Ajzen 1975). They have been used extensively as surrogates of behavior especially in situations where in the technology was not widely used or prior to deployment of certain technologies (Amaro and Duarte 2015). In this study, given that travel to hotels has not returned to the pre-pandemic capacity, it is unfeasible to collect data on the use of TSD in hotels. Therefore, this study conceptualizes intentions to use TSD in hotels as the main dependent variable. However, this study also recognizes the specific character of two types of TSD in hotels, namely personal and public. Personal technologies are likely to be used extensively during the pandemic because the risk of contamination is lower. In such situations, consumers do not have to touch any publicly available system, and the hotels could rely heavily on these systems to enhance social distancing. However, hotels also offer technologies that are publicly available, and they require customers to touch a device. In these conditions, customers may have different motivations to use one type of system versus the other, therefore calling for the utilization of constructs reflecting these two types of systems. The conceptual model is represented in the Fig. 1 below.

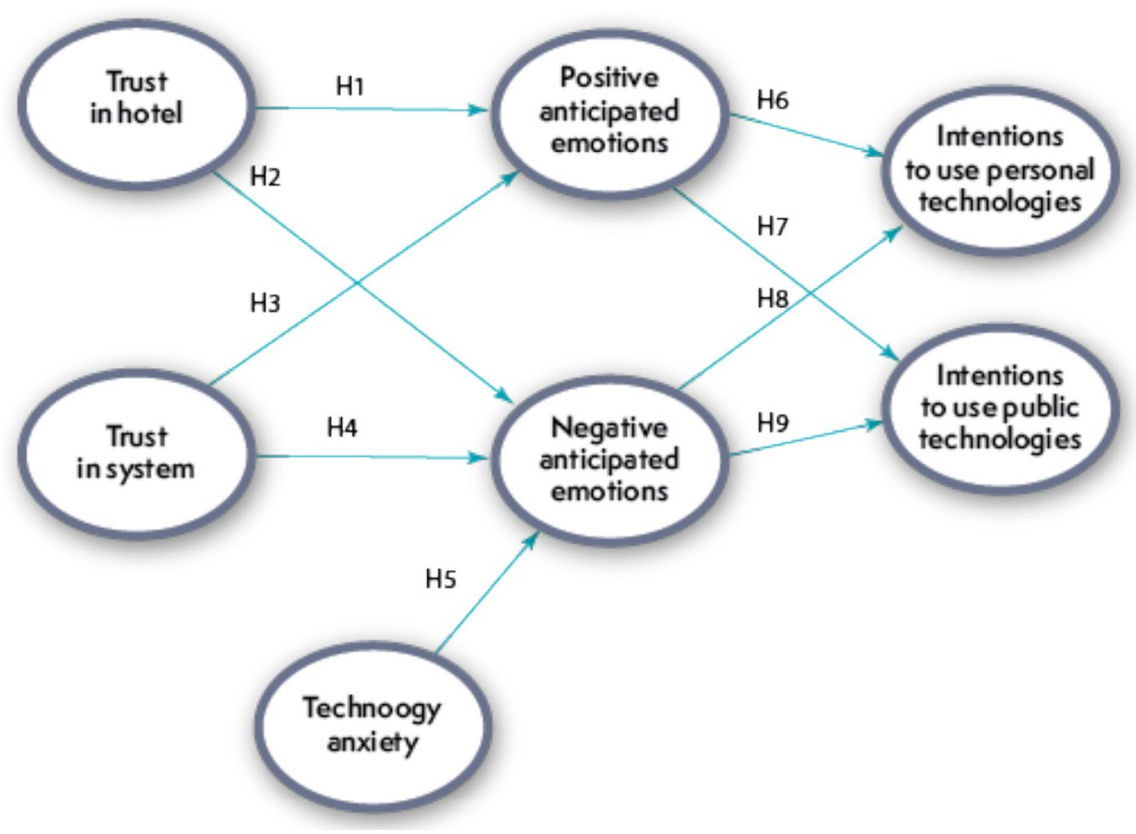

Fig. 1 Conceptual model and hypotheses 


\section{Methods}

\subsection{Instrument design}

The scales were adapted from published studies and are presented in the Appendix. Anticipated emotions were measured with ten items (five for positive anticipated emotions and five for negative anticipated emotions) adapted from (Perugini and Bagozzi 2001). Trust in the hotel was operationalized using three items adapted from Norberg and Horne (2007) while trust in the system was measured with three items adapted from Anderson and Agarwal (2011). Technology anxiety was measured with six items adapted from Lee and Yang (2013). The items were measured on 5-point Likert-type scales with values ranging from 1 (strongly disagree) to 5 (strongly agree).

Intentions were adapted from Venkatesh et al. (2012) and were operationalized such that each item reflected respondents' likelihood of using a specific system (e.g., mobile app, touchless payments). There were three items measuring intentions to use personal technologies (e.g., mobile app, mobile touchless payments, electronic menu accessible via personal computing devices) and public technologies (i.e., touch-screen kiosk, touch-screen device located in guest room, standalone guestroom technology). All six intentions items were measured via Likert-type scales ranging from 1 (not likely at all) to 5 (very likely) to use the specified technologies.

The survey began with a description of a fictive scenario, where the respondent had to imagine that they are about to stay at a hotel that had deployed TSD. The respondents were asked to imagine that their hotel tasks (e.g., check-in, payment) could be completed using TSD in addition to staff members (similar to prepandemic). A list of examples of TSD was also provided to respondents. This procedure is popular in social science research, including in studies eliciting emotions (Bufquin et al. 2020; Kuo et al. 2015), as respondents are capable of feasibly assessing their emotional reactions to the level of risk described of the scenario. This approach is also common in research involving IT (Bettiga and Lamberti 2018), especially when using a system can involve various types of risk (e.g., security, privacy) (Morosan 2018). The instrument concluded with a demographic and behavioral section (Table 1).

\subsection{Instrument deployment}

Data were collected in July 2020 from a sample of U.S. consumers using the services of a marketing panel company. The company provided access to a sample of consumers recruited from the general population and charged a fixed amount each time a respondent completed the survey. Individuals recruited from the U.S. population who have stayed in a hotel during a period of 24 months prior to the study. The reason for recruiting hotel guests is the relevancy and relative recency of the hotel stay experience prior to the pandemic and economic shutdown. The reason for selecting the U.S. market is the researchers' familiarity with the U.S. 
Table 1 Demographic and behavioral profile of respondents

$$
\text { C }
$$

Characteristic

Age

29 or younger

30-49

50 or older

Gender

Male

Female

Not disclosed

Annual household income

$\$ 50,000$ or less

$\$ 50,001-\$ 100,000$

$\$ 100,001-\$ 200,000$

Over $\$ 200,000$

Highest level of education

High school degree or equivalent

Bachelor of Science/Arts or equivalent

Graduate degree or equivalent

Other

Frequency of stay in hotels

Less than once a year

1 to 6 times a year

7 or more times a year

Stay duration

1 to 3 nights

4 to 7 nights 25.9

8 or more nights

Hotel class

Luxury

Upscale and upper-upscale

Midscale and upper-midscale

Economy and others

Purpose of travel

Predominantly business

Combined business and leisure

Predominantly leisure

hotel market and the technologies and business models that are currently in use in the U.S. This pricing model required the establishment of a target sample size, which met the requirements of the conceptual model of this study and in line with the budget of this study. Therefore, based on the recommendations of Hair et al. (2009), a target sample size of 1000 respondents was established. The panel company sent the recruiting message and the link to the survey to their panelists, and 
the data collection continued until the target sample size was reached and slightly exceeded.

\section{Results}

\subsection{Preliminary results-demographic and behavioral}

The preliminary results are presented in Table 1 . The predominant age group is between 30 and 49 years old (41.3\%), followed by the consumers who are 50 or older $(33.9 \%)$. The genders were equally balanced, with females accounting for $50.9 \%$ of the sample. In terms of annual household income, most respondents had between 50,001 and \$100,000 per year (40.8\%). Most people had a Bachelor of Science/Arts degree (40\%) followed by a high school degree or equivalent $(31.3 \%)$. The survey also used several items to gauge the hotel staying behavior of respondents. In terms of frequency of staying in hotels, most respondents stayed between one and six times a year (69.7\%). About two thirds of the sample stayed between one and three nights in a typical stay $(66.5 \%)$. The respondents stayed mostly in midscale and upper midscale hotels (50.2\%) and traveled predominantly for leisure (67\%).

\subsection{Confirmatory factor analysis results}

The modeling technique utilized in this study required the utilization of a confirmatory factor analysis (CFA) followed by a structural equation modeling (SEM) (Hair et al. 2009). Both analyses were conducted using Mplus 8.0 (Muthèn and Muthèn 2017). The first step was to determine whether the instrument displayed the appropriate psychometric properties, which used the results from the CFA. To determine which estimator to use in the CFA, a multivariate normality test was conducted using Mardia's coefficients (Mardia 1970). The analysis revealed that the data set did not meet the condition of multivariate normality. Multivariate normality is not a serious problem today, as most SEM software include estimators that are robust to deviations from multivariate normality. Therefore, the CFA utilized an estimator that is robust to multivariate non-normality (Mardia 1970). The CFA model had a good fit, characterized by the following fit indexes: chi-squared: 709.202, degrees of freedom: 230, normed chi-squared: 3.08, Comparative Fit Index (CFI): 0.957, Tucker-Lewis Index (TLI): 0.948, and Root Mean Squared Error of Approximation (RMSEA): 0.045 (Toh et al. 2006).

The CFA provided that data necessary to assess reliability and validity. First, reliability was assessed by calculating the composite construct reliability (CCR) scores for all latent variables (Hair et al. 2009) (Table 2). All of the CCR values exceeded the commonly-accepted threshold of 0.7 , therefore demonstrating appropriate reliability (Hair et al. 2009). The analysis continued with an assessment of convergent and discriminant validity. To assess convergent validity, the average values extracted (AVE) scores were calculated for all latent variables using the loadings for each item in the model (Table 3). As all AVE scores exceeded the commonly used threshold 
Table 2 Reliability and validity testing

Construct/items

CCR/loadings

(sq. loadings)

ANTICIPATED EMOTIONS (positive) (adapted from Perugini and Bagozzi 2001)

0.895

Generally, if I successfully use technology for social distancing in hotels, I would feel...

1. Self-assured

$0.684(0.468)$

2. Excited

$0.896(0.803)$

3. Delighted

$0.887(0.787)$

4. Proud

$0.822(0.676)$

ANTICIPATED EMOTIONS (negative) (adapted from Perugini and Bagozzi 2001)

0.888

Generally, if I do NOT succeed at using technology for social distancing in hotels, I would feel...

1. Worried

$0.712(0.507)$

2. Uncomfortable

$0.771(0.594)$

3. Guilty

$0.759(0.576)$

4. Frustrated

$0.832(0.692)$

5. Sad

TRUST IN HOTEL (adapted from Norberg and Horne 2007)

$0.839(0.704)$

0.838

1. The hotel offering technology for social distancing is generally trustworthy

$0.817(0.667)$

2. The hotel offering technology for social distancing gives me the impression that it keeps its promises and commitments

3. The hotel offering technology for social distancing has my best interests in mind

$0.798(0.637)$

$0.771(0.594)$

0.782

1. I believe that technology for social distancing represent secure systems through which to send sensitive information

2. I would feel secure providing personal information via technology for social distancing in hotels

TECHNOLOGY ANXIETY (Adapted from Lee and Yang 2013)

$0.789(0.623)$

$0.814(0.663)$

1. I feel apprehensive about using technology

\subsection{2}

$0.718(0.516)$

$0.830(0.689)$

0.827 (0.684)

3. Technological terminology sounds like confusing jargon to me

$0.848(0.719)$

4. I have avoided technology because it is unfamiliar to me

0.817

From the technologies listed below, which one(s) are you likely to use to maintain social distancing in hotels?

1. Hotel mobile app

$0.816(0.666)$

$0.757(0.573)$

2. Mobile (touchless) payments

$0.746(0.557)$

3. Electronic menu accessible using my own devices

0.822

From the technologies listed below, which one(s) are you likely to use to maintain social distancing in hotels?

1. Touch-screen kiosks at front desk or lobby area

$0.790(0.624)$

2. Touch-screen device located in guest room (e.g., tablet)

$0.848(0.719)$

3. Standalone guestroom technology

$0.694(0.482)$

The composite construct reliabilities (CCR) are represented in bold and squared loadings are represented in parentheses 


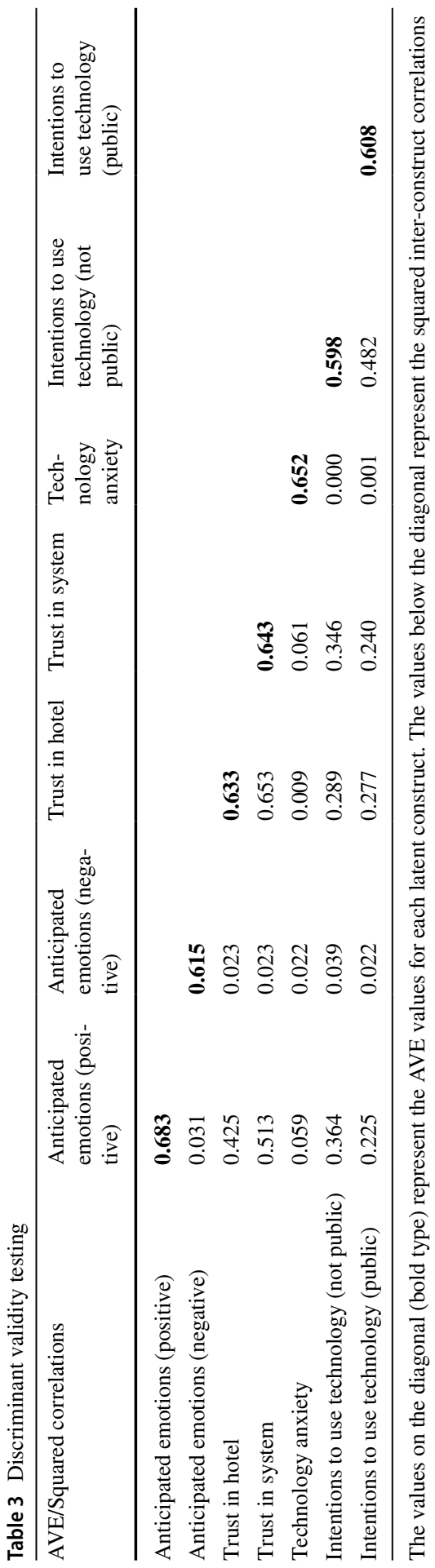


of 0.5 , it was concluded that the instrument has appropriate convergent validity. In addition, the item loadings exceeded 0.7 or were close to 0.7 , indicating appropriate convergent validity (Hair et al. 2009).

The final step was to assess discriminant validity. The AVE scores were compared with all the squared inter-construct squared correlation (Fornell and Larcker 1981). Discriminant validity is established when each inter-construct correlation is lower than the AVE corresponding to each corresponding construct (Fornell and Larcker 1981). In this study, all but one inter-construct correlations were lower than the corresponding AVE scores. The one correlation value that was higher than the AVE scores was the squared correlation between trust in hotel and trust in system, and it was within 7\% from the corresponding AVE values. This analysis indicated that the instrument is characterized by appropriate discriminant validity, providing the last results that confirm that this instrument has proper psychometric properties and can be used to test model fit and obtain data for hypothesis testing.

\subsection{SEM modeling results}

Overall the SEM model had a good fit, based on the following indexes: chisquared 804.498, degrees of freedom: 238, normed chi-squared: 3.38 , CFI: 0.949, TLI: 0.940, and RMSEA: 0.048 (Toh et al. 2006) (Fig. 2). This confirms that this model is appropriate for hypothesis testing. Of the nine proposed hypotheses, six were supported. Specifically, trust in hotel was found to be a significant predictor

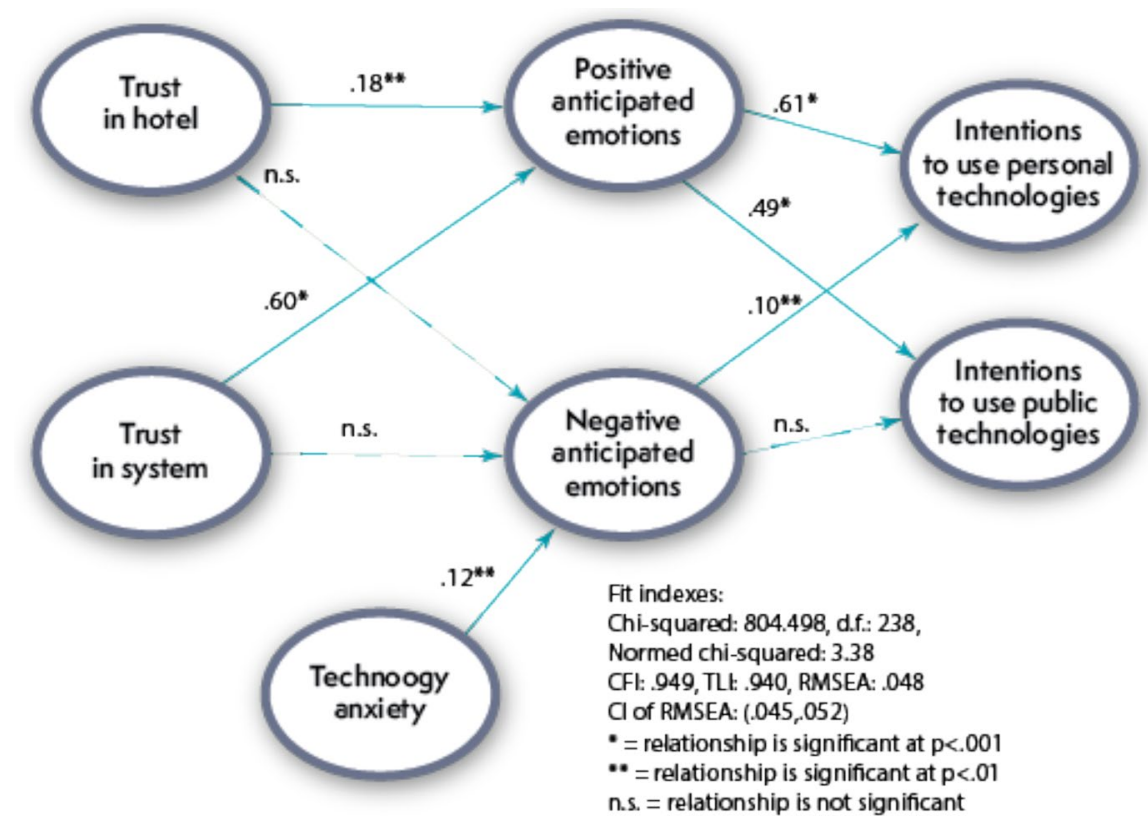

Fig. 2 Model test results 
of anticipated positive emotions $(\gamma=0.18, p<0.01)$ but did not significantly influenced the anticipated negative emotions. Therefore, hypothesis H1 was supported but hypothesis $\mathrm{H} 2$ was not. Trust in system was also found to significantly influence anticipated positive emotions $(\gamma=0.60, p<0.001)$ but not anticipated negative emotions. This result provides support for hypothesis $\mathrm{H} 3$, while hypothesis $\mathrm{H} 4$ was not supported. Technology anxiety was a significant predictor of anticipated negative emotions $(\gamma=0.12, p<0.01)$, therefore supporting hypothesis H5. In turn, anticipated positive emotions significantly influenced intentions to use personal TSD $(\beta=0.61, p<0.001)$ and public TSD $(\beta=0.49, p<0.001)$, supporting hypotheses H6 and H7. Anticipated negative emotions was a significant predictor of intentions to use personal TSD $(\beta=0.10, p<0.01)$, it was not a significant predictor of intentions to use public TSD. Therefore, hypothesis H8 was supported and hypothesis H9 was not supported.

\section{Discussion}

The relationship between trust in the hotel and anticipated positive emotions was significant but low. This means that customers' trust in the hotel translates into their positive emotions regarding the use of technology for social distancing in hotels. This result reinforces the notion that the hotel represents an agent that the consumers generally trust, even in situations as extreme as a global pandemic. Moreover, trust in the hotel provides an overall motivational foundation for the anticipated positive emotions to develop, which represents an important confirmation of the literature that establishes evaluations of relationships (such as trust) as precursors of emotions. However, the low magnitude of this relationship indicates that the role of trust in the development of positive anticipated emotions is limited. In the context of technology, this may be explained by companies deploying technologies that vary in their level of intentions to use by consumers. In contrast, trust in the system was validated as a relatively stronger predictor of anticipated positive emotions. This result, which is in line with the existing literature, reinforces the idea that while hotels deploy various types of technologies, it is the evaluation of a specific technology that represents the main foundation for the development of positive anticipated emotions regarding the use of that technology. While this is not surprising, it is important to note that the TSD in hotels have the capability of stimulating quite strongly consumers' positive anticipated emotions, as consumers evoke feelings of self-assurance and excitement, given the role of technology in preventing contamination.

Surprisingly, neither trust in the hotel nor trust in the system were found to be significant predictors of anticipated negative emotions. This result stands out from the existing literature, which generally accepts that trust can influence negative emotions and can be explained by the general anxieties of consumers regarding hotels and interacting with hotels via IT. The only significant predictor of anticipated negative emotions is technology anxiety. This low relationship is consistent with the literature and can be explained by the common motivational fabric that stays at the foundation of both technology anxiety and anticipated negative emotions. In addition to the natural anxiety that is related to using hotel technology with which some users 
may be unfamiliar, the anxiety exacerbated by the pandemic may be elevated, which can strengthen the influence of technology anxiety on anticipated negative emotions. However, the low magnitude of this relationship could indicate that consumers' preexisting attitudes toward technology can influence the perceived importance of using such technologies for social distancing. Specifically, consumers who fear technology are likely to feel uncomfortable, worried, or frustrated in anticipation of their use of technology for a task that is primordial: protecting against the coronavirus.

Intentions to use personal technology were influenced by both types of emotions, with positive anticipated emotions being the strongest predictor. That is, consumers who are excited about the use of TSD are likely to develop strong intentions to use personal TSD. This result can be explained by the fact that consumers that effectively anticipate their reliance on TSD are likely to be sufficiently motivated to interact with the hotel using personal technologies. Such consumers may see such technologies as a shield that protects them against infection, in a context in which they are still expecting some interactions with the hotel. In contrast, there is only a low impact of negative emotions on consumers' intentions to use personal technology. As these results are explored in the context of this study for the first time, there is no literature benchmark to compare against.

With respect to intentions to use public technologies, anticipated positive emotions was a significant predictor, while anticipated negative emotions was not. That is, consumers who feel positive about their use of TSD are likely to use even public technologies in hotels. This result, which aligns with the literature on emotions (Morosan 2018), may be explained by the fact that consumers may feel confident about their ability to use such technologies in a way that facilitates social distancing are likely to feel protected enough to use public technologies. In the current context, this result is notable, as hotels find it difficult to anticipate consumers' use of public technologies, while some guests may be skeptical about the use of such technologies. Moreover, this result outlines that the current pandemic changed the way consumers view the public technology in hotels. The non-significant relationship between negative anticipated emotions and the use of public technologies is also notable. It can be explained by the fact that consumers who develop negative emotions may respond in an unpredicted manner to situations that require their use of public TSD.

\section{Implications}

\subsection{Implications for theory}

The study set out to address three major gaps in the current literature in IT and hospitality at a crucial time in its history_during a global pandemic. The study validated relationships that explain consumers' intentions to use TSD technology in hotels during the pandemic, therefore bringing several critical implications for theory. Addressing the first gap-the unknown adoption behaviors of consumers during irregular business conditions (i.e., pandemic) — this study was able to explicate consumers' intentions to use IT in a way that facilitates social 
distancing. While intentions to use specific IT in hotels has been a perennial subject of research in hospitality, this is the first study that acknowledges that IT can be used to accomplish other tasks than efficiency and convenience in uncommon situations. Thus, the study occupies a unique position in the literature that elucidates consumer behavior using IT, and represents an integral part of the novel research effort aimed at understanding consumers' use of IT in hospitality during the pandemic. Moreover, this study offers insight into how the build conceptual models that are grounded in an altered task-technology environment (relative to regular operations). In doing so, this study expands the scope of the task-technology environment in IT adoption research and broadens the theoretical basis of the IT adoption literature.

Addressing the second gap, this study built a conceptual model based predominantly on emotional constructs. There are several important implications resulting from this approach. This study examines the relationships among these constructs during the pandemic, when consumers are motivated by different factors (e.g., health risk) to use TSD. In addition, this study conceptualizes both positive and negative anticipated emotions as antecedents of behavior, which has not been studied extensively in service settings where the risk of not using a specific technology is associated with potential harmful consequences for one's health. Also, by focusing on anticipated valenced emotions, this study brings an important level of understanding of the way the relationship between emotions and behavior forms in an IT task environment dominated by risk. Moreover, this study conceptualizes technology anxiety in a model based predominantly on emotions. As such, the study expands the body of literature that focuses predominantly on drivers of technology use, instead of inhibitors. Yet, as such inhibitors are important in driving consumers away from specific technologies, this study validates the notion that IT adoption in highly experiential settings like hotels is more nuanced than initially thought when the models were based only on cognitive, positive antecedents of intentions to use. Given these implications, this study broadens the scope of the IT literature and provides a road map of consumers' IT utilization under non-voluntary adoption conditions.

In response to the third gap, this study conceptualizes consumers' intentions to use TSD by grouping this construct into two distinct sub-constructs. This way, this study occupies a unique position in the literature, which predominantly groups all the technologies into a single construct, without necessarily recognizing the innate differences among the various types of technologies. The implications for the IT literature of this conceptualization are multiple. For example, by recognizing that personal technologies could be perceived to be less risky by the consumers, especially during the pandemic, relative to public technologies, it is possible now to advance the thesis that technology perceptions can be more nuanced than initially thought to be, even when multiple technologies can be grouped under the same category based on the tasks they facilitate. Moreover, even in normal business conditions, after the pandemic, such conceptualizations can lead to a deeper understanding of the differential ways in which consumers form intentions to use various technologies in hotels, depending on the nature of use (e.g., private vs. public). Thus, this study provides an innovative platform for the conceptualization of intentions in IT adoption and opens the door for a more granular approach to its examination. 


\subsection{Implications for practice}

This study also offers several important implications for hotels. First, noting that both trust in hotel and trust in system influence consumers' positive anticipated emotions, consumers should be exposed to information that capitalizes on trust. For example, given that most U.S. properties are branded, hotels can design strategies that take advantage of the brand image to stimulate positive anticipated emotions pertaining to the use of TSD. Specifically, hotels can provide short communications or demos of how to use TSD in hotels, which could also enhance consumers positive anticipated emotions. Moreover, hotels can rely on their relationships with their loyal customers, which are grounded in trust, to continue to stimulate the trusting relationship with these consumers and eventually enhance their positive anticipated emotions relative to TSD.

Hotels can also capitalize on the low impact of technology anxiety on consumers' negative anticipated emotions. This result should be reassuring for both hotels and technology vendors, as such technologies are not met with resistance in the marketplace. However, whenever present, technology anxiety leads to negative anticipated emotions, which put the consumers in a situation where they are uncomfortable with any inability to use TSD. If they cannot use TSD, they intensify their negative emotions as they encounter more risk, given that they are supposed to interact with staff. Additionally, hotels can find further reassurance in the fact that there is no relationship between trust either in the hotel or the system and anticipated negative emotions. There may be other causes that influence such negative anticipated emotions, and the hotels can continue to cultivate a trusting relationship with their consumers to stimulate the positive anticipated emotions relative to the use of TSD.

Perhaps the most important implication for the hotels is that both types of anticipated emotions can stimulate consumers' intentions to use TSD. One way to accomplish this is through hotels' marketing material. In the era short videos and aided by a strong social media presence, hotels can provide explanatory material about how to use TSD. Hotels can provide testimonials from consumers who feel excited or display positive emotions when using TSD. Moreover, hotels can convey the information that TSD are in use on that particular property from the moment the hotel sends the confirmation of a reservation. In addition, hotels can encourage the consumers who are using these technologies and are already on the property to provide reviews online about how they were able to complete various hotels tasks using TSD. Because the anticipated positive emotions are strong predictors of intentions to use both types of TSD, it is important that hotels use positive emotional appeals in their communication. Given that the anticipated negative emotions have a very low impact on the use of THD in hotels, hotels could remove cues that stimulate such emotions from their communications.

\section{Limitations and directions for further research}

The nature of this study is associated with several inevitable limitations. First, the data were collected in the U.S., therefore reflecting the motivations of American consumers to use technology in hotels during the pandemic. This reflects not 
only American consumers' travel habits and health-related motivations, but also their approach to social distancing. This is a limitation because these results, while generalizable to the entire U.S. population, cannot be generalized beyond that. To address this limitation and capitalize on the global character of the hotel industry, the study could be replicated in settings beyond the U.S. Second, this study recognizes the importance of including cognitive antecedents of IT-related behavior. While this study relied predominantly on emotional antecedents of intentions, mixed models that combine cognitive and affective constructs can be developed to expand the ability to capture the full motivational structure of consumers using TSD. Specifically, models that include dominant variables such as perceived usefulness, ease of use, and social influences should be considered. As hotels are changing their IT infrastructure, it would be critical to understand how the consumers view the use of certain systems, as reflected by their evaluations communicated via word of mouth. Thus, taking a data mining approach to understanding the consumers' perceptions of TDS will be beneficial as it would provide an evaluation of a tangible aspect of hotel services, which would contrast with today's predominant reviews that focus mostly on intangible aspects (e.g., staff, communication).

Third, as this study investigated trust in system, trust in hotels, and technology anxiety as parts of an integrated model, future studies could investigate more indepth the relationships between trust in systems, trust in hotels, and general technology anxiety in standalone models. This is important because of the current differentiation between the brands of particular systems used in hotels and the hotel brands. For example, highly popular IT brands such as Apple, Google could stimulate consumers' trust, which can be different than trust toward the hotel brands, especially in the wake of IT security incidents such as breaches, etc. Finally, this study focused on the most common technologies that were re-tasked to facilitate social distancing. As technology advances and the response of the hotel industry to the pandemic is better understood, hotels may deploy other technologies that facilitate prevention from infection with coronavirus. Therefore, future research could examine technologies such as automated cleaning devices or robots that diminish the need of consumers to interact with hotel staff. However, being the first study to examine customers' emotional responses to TSD and their influence on behavior, this study provides the initial blueprint for a potential stream of studies that could comprehensively examine the new vision for IT in hotels: safeguarding health.

\section{Declarations}

Conflict of interest The author declare that there are no conflicts of interests regarding this manuscript.

\section{References}

Ahn JA, Seo S (2018) Consumer responses to interactive restaurant self-service technology (IRSST): the role of gadget-loving propensity. Int J Hosp Manag 74:109-121

Akroush MN, Al-Debei MM (2015) An integrated model of factors affecting consumer attitudes towards online shopping. Bus Process Manag J 21(6):1353-1376 
Akrout H, Nagy G (2018) Trust and commitment within a virtual brand community: the mediating role of brand relationship quality. Inf Manag 55(8):939-955

Amaro S, Duarte P (2015) An integrative model of consumers' intentions to purchase travel online. Tour Manag 46:64-79

Anderson CL, Agarwal R (2011) The digitization of healthcare: boundary risks, emotion, and consumer willingness to disclose personal health information. Inf Syst Res 22(3):469-490

Beaudry A, Pinsonneault A (2010) The other side of acceptance: studying the direct and indirect effects of emotions on information technology use. MIS Q 34(4):689-710

Bettiga D, Lamberti L (2018) Exploring the role of anticipated emotions in product adoption and usage. J Consum Mark 35(3):300-316

Blanchette I, Richards A (2010) The influence of affect in higher level cognition: a review of research on interpretation, judgement, decision making and reasoning. In: de Houwer J, Hermans D (eds) Cognition and emotion: reviews of current research and theories. Psychology Press, New York

Bonfanti A, Vigolo V, Yfantidou G (2021) The impact of the Covid-19 pandemic on customer experience design: the hotel managers' perspective. Int J Hosp Manag 94:102871

Brosch T, Pourtois G, Sander D (2010) The perception and categorisation ofemotional stimuli: a review. In: de Houwer J, Hermans D (eds) Cognition and emotion: reviews of current research and theories. Taylor \& Francis Group, pp 66-98

Brown SA, Fuller RM, Vician C (2004) Who's afraid of the virtual world? Anxiety and computer-mediated communication. J Assoc Inf Syst 5(2):79-107

Bufquin D, Park J-Y, Back RM, Nutta MWW, Zhang T (2020) Effects of hotel website photographs and length of textual descriptions on viewers' emotions and behavioral intentions. Int J Hosp Manag $87: 102378$

Cenfetelli RT (2004) Getting in touch with our feelings towards technology. In: Paper presented at the best paper proceedings of the academy of management conference, New Orleans

Chan ESW, Lam D (2013) Hotel safety and security systems: bridging the gap between managers and guests. Int J Hosp Manag 32:202-216

Chien PM, Sharifpour M, Ritchie BW, Watson B (2017) Travelers' health risk perceptions and protective behavior: a psychological approach. J Travel Res 56(6):744-759

Cobos LM, Mejia C, Ozturk AB, Wang Y (2016) A technology adoption and implementation process in an independent hotel chain. Int J Hosp Manag 57:93-105

Cochard F, Van PN, Willinger M (2004) Trusting behavior in a repeated investment game. J Econ Behav Organ 55(1):31-44

Davidson RJ, Irwin W (1999) The functional neuroanatomy of emotion and affective style. Trends Cogn Sci 3:1121

de Houwer J, Hermans D (2010) Introduction. In: de Houwer J, Hermans D (eds) Cognition and emotion: reviews of current research and theories. Taylor \& Francis Group, New York

Escobar-Rodríguez T, Carvajal-Trujillo E (2014) Online purchasing tickets for low cost carriers: an application of the unified theory of acceptance and use of technology (UTAUT) model. Tour Manag 43:70-88

Fang Y, Qureshi I, Sun H, McCole P, Ramsey E, Lim KH (2014) Trust, satisfacton, and online repurchase intention: the moderating role of perceived effectiveness of e-commerce institutional mechanisms. MIS Q 38(2):407-427

Fishbein M, Ajzen I (1975) Beliefs, attitudes, intentions, and behavior: an introduction to theory and research. Addison-Wesley, Reading

Fornell C, Larcker D (1981) Structural equation models with unobservable variables and measurement error. J Mark Res 18(1):39-50

George JM, Dane E (2016) Affect, emotion, and decision making. Organ Behav Hum Decis Process 136:47-55

Gleicher F, Boninger DS, Strathman A, Armor D, Hetts J, Ahn M (1995) With an eye toward the future: the impact of counterfactual thinking on aåect, attitudes, and behaviour. In: Roese NJ, Olson MM (eds) What might have been: the social psychology of counterfactual thinking. Erlbaum, Mahwah, pp 283-304

Guszkowski J (2020) All of a sudden, QR codes are everywhere. Restaurant Business. Retrieved from restaurantbusinessonline.com website: https://www.restaurantbusinessonline.com/technology/allsudden-qr-codes-are-everywhere

Hair JF, Black WC, Babin BB, Anderson RE (2009) Multivariate data analysis, 7th edn. Prenticel Hall, Upper Saddle River 
Harkison T (2018) The use of co-creation within the luxury accommodation experience-myth or reality? Int J Hosp Manag 71:11-18

Kim J, Forsythe S (2008) Adoption of virtual try-on technology for online apparel shopping. J Interact Mark 22(2):45-59

Kim YJ, Njite D, Hancer M (2013) Anticipated emotion in consumers' intentions to select eco-friendly restaurants: augmenting the theory of planned behavior. Int J Hosp Manag 34:255-262

Kohlmayr K (2020) How being smart and nimble will help hoteliers survive years of flux. PhocusWire. Retrieved from https://www.phocuswire.com/revenue-management-hotels-covid-19-ideas

Kotler PT, Bowen JT, Makens J, Baloglu S (2016) Marketing for hospitality and tourism, 7th edn. Pearson, New York

Koufaris M (2002) Applying the technology acceptance model and flow theory to online consumer behavior. Inf Syst Res 13(2):205-223

Kuo P-J, Zhang L, Cranage DA (2015) What you get is not what you saw: exploring the impacts of misleading hotel website photos. Int J Contemp Hosp Manag 27(6):1301-1319

Lacasse K (2017) Going with your gut: How William James' theory of emotions brings insights to risk perception and decision making research. New Ideas Psychol 46:1-7

Lee H-J, Yang K (2013) Interpersonal service quality, self-service technology (SST) service quality, and retail patronage. J Retail Consum Serv 20(1):51-57

Liang LJ, Choi HC, Joppe M (2018) Exploring the relationship between satisfaction, trust and switching intention, repurchase intention in the context of Airbnb. Int J Hosp Manag 69:41-48

Lien C-H, Hsu MK, Shang J-Z, Wang SW (2019) Self-service technology adoption by air passengers: a case study of fast air travel services in Taiwan. Serv Ind J. https://doi.org/10.1080/02642069.2019. 1569634

Liu C, Marchewka JT, Lu J, Yu C-S (2005) Beyond concern-a privacy-trust-behavioral intention model of electronic commerce. Inf Manag 42(2):289-304

Mardia KV (1970) Measures of multivariate skewness and kurtosis with applications. Biometrika 57(3):519-530

Marques L, Borba C (2017) Co-creating the city: digital technology and creative tourism. Tourism Manag Perspect 24:86-93

Mayer R, Davis J, Schoorman F (1995) An integrative model of organizational trust. Acad Manag Rev 20:709-734

Mishra A, Shukla A, Rana NP, Dwivedi YK (2020) From "touch" to a "multisensory" experience: the impact of technology interface and product type on consumer responses. Psychol Mark $38(3): 385-396$

Moors A (2010) Theories of emotion causation: a review. In: De Houwer J, Hermans D (eds) Cognition and emotion: reviews of current research and theories. Taylor \& Francis Group, New York, pp 1-37

Morosan C (2016) An empirical examination of U.S. travelers' intentions to use biometric e-gates in airports. J Air Transp Manag 55:120-128

Morosan C (2018) Information disclosure to biometric e-gates: the roles of perceived security, benefits, and emotions. J Travel Res 57(5):644-657

Morosan C (2020) Hotel facial recognition systems: insight into guests/system perceptions, congruity with self image, and anticipated emotions. J Electron Commer Res 21(1):21-38

Morosan C, DeFranco A (2015) Disclosing personal information via hotel apps: a privacy calculus perspective. Int J Hosp Manag 47:120-130

Morosan C, DeFranco A (2016a) Co-creating value in hotels using mobile devices: a conceptual model with empirical validation. Int J Hosp Manag 52:131-142

Morosan C, DeFranco A (2016b) It's about time: revisiting UTAUT2 to examine consumers' intentions to use NFC mobile payments in hotels. Int J Hosp Manag 53:17-29

Morosan C, DeFranco A (2016c) Modeling guests' intentions to use mobile apps in hotels. Int J Contemp Hosp Manag 28(9):1968-1991

Morosan C, DeFranco A (2019) Using interactive technologies to influence guests' unplanned dollar spending in hotels. Int J Hosp Manag 82:242-251

Morosan C, Jeong M (2008) Users' perceptions of two types of hotel reservation Web sites. Int J Hosp Manag 27(2):284-292

Muthèn LK, Muthèn BO (2017) Mplus User's Guide. 8th edn., vol 2017, Muthén\& Muthén, Los Angeles, CA

Norberg PA, Horne DR (2007) Privacy attitudes and privacy-related behavior. Psychol Mark 24(10):829-847 
Nyheim PD, Connolly DJ (2012) Technology strategies for the hospitality industry. Pearson

Palvia P (2009) The role of trust in e-commerce relational exchange: a unified model. Inf Manag 46(4):213-220

Parasuraman A (2000) Technology Readiness Index (TRI): a multiple-item scale to measure readiness to enbrace new technology. J Serv Res 2(4):307-320

Park J, Ahn J, Thavisay T, Ren T (2019) Examining the role of anxiety and social influence in multibenefits of mobile payment service. J Retail Consum Serv 47:140-149

Park SS, Tung CD, Lee H (2021) The adoption of AI service robots: a comparison between credence and experience service settings. Psychol Mark 38(4):691-703

Parker D, Manstead ASR, Stradling SG (1995) Extending the theory of planned behaviour: the role of personal norm. Br J Soc Psychol 34:127-137

Perugini M, Bagozzi RP (2001) The rol of desires and anticipated emotions in goal-directed behaviours: broadening and deepening the theory of planner behaviour. Br J Soc Psychol 40:79-98

Piçarra N, Giger J-C (2018) Predicting intention to work with social robots at anticipation stage: assessing the role of behavioral desire and anticipated emotions. Comput Hum Behav 86:129-146

Rafaeli A, Vilnai-Yavetz I (2004) Emotion as a connection of physical artifacts and organizations. Organ Sci 15(6):671-686

Richard M-O, Chebat J-C (2016) Modeling online consumer behavior: Preeminence of emotions and moderating influences of need for cognition and optimal stimulation level. J Bus Res 69(2):541-553

Richard R, van der Pligt J, de Vries N (1995) Anticipated affective reactions and prevention of AIDS. Br J Soc Psychol 34:9-21

Salehi-Esfahani S, Kang J (2019) Why do you use Yelp? Analysis of factors influencing customers' website adoption and dining behavior. Int J Hosp Manag 78:179-188

Sarmah B, Kamboj S, Rahman Z (2017) Co-creation in hotel service innovation using smart phone apps: an empirical study. Int J Contemp Hosp Manag 29(10):2647-2667

Shao Z, Zhang L, Li X, Guo Y (2019) Antecedents of trust and continuance intention in mobile payment platforms: the moderating effect of gender. Electron Commerce Res Appl 33:100823

Shao J, Bai H, Shu S, Joppe M (2020) Planners' perception of using virtual reality technology in tourism planning. e-Rev Tourism Res 17(5):685-695

Sheppard B, Sherman D (1998) The grammars of trust: a model and general implications. Acad Manag Rev 23(3):422-537

Shin H, Kang J (2020) Reducing perceived health risk to attract hotel customers in the COVID-19 pandemic era: focused on technology innovation for social distancing and cleanliness. Int J Hosp Manag 91:102664

Solay (2020) Solay App provides social distancing technology for resort pools \& beaches. Hotel News Resource. Retrieved from https://www.hotelnewsresource.com/article110855.html

Toh RS, Lee E, Hu MY (2006) Social desirability bias in diary panels is evident inpanelists' behavioral frequency. Psychol Rep 9(2):322-334

Trevino LK, Webster J (1992) Flow in computer-mediated communication: electronic mail and voice mail evaluation and impacts. Commun Res 19(5):539-573

Tsaur S-H, Luoh H-F, Syue S-S (2015) Positive emotions and behavioral intentions of customers in fullservice restaurants: does aesthetic labor matter? Int J Hosp Manag 51:115-126

Venkatesh V, Morris MG, Davis GB, Davis FD (2003) User acceptance of information technology: toward a unified view. MIS Q 27:425-478

Venkatesh V, Thong JY, Xu X (2012) Consumer acceptance and use of information technology: extending the unified theory of acceptance and use of technology. MIS Q 36(1):157-178

Wang P, Li H (2019) Understanding the antecedents and consequences of the perceived usefulness of travel review websites. Int J Contemp Hosp Manag 31(3):1086-1103

Wang L, Law R, Guillet BD, Hung K, Fong DKC (2015) Impact of hotel website quality on online booking intentions: eTrust as a mediator. Int J Hosp Manag 47(1):108-115

Wang X, Peng L, Xu F, Luo XR (2018) Do incentives in SWOM communication matter? A positive emotion perspective. J Electron Commer Res 19(2):135-153

Wei W, Torres EN, Hua N (2017) The power of self-service technologies in creating transcendent service experiences. Int J Contemp Hosp Manag 29(6):1599-1618

Westbrook RA (1987) Product/consumption-based affective responses and postpurchase processes. J Mark Res 24:258-270 
Yang K, Forney JC (2013) The moderating role of consumer technology anxiety in mobiel shopping adoption: differential effects of facimitating conditions and social influences. $\mathrm{J}$ Electron Commer Res 14(4):334-349

Yousafzai SY, Pallister JG, Foxall GR (2005) Strategies for building and communicating trust in electronic banking: a field experiment. Psychol Mark 22(2):181-201

Zimmer JC, Arsal RE, Al-Marzouq M, Grover V (2010) Investigating online information disclosure: effects of information relevance, trust, and risk. Inf Manag 47(2):115-123

Publisher's Note Springer Nature remains neutral with regard to jurisdictional claims in published maps and institutional affiliations. 